University of Nebraska - Lincoln

DigitalCommons@University of Nebraska - Lincoln

Agronomy \& Horticulture -- Faculty Publications

Agronomy and Horticulture Department

2014

Phytophthora Root Rot Resistance in Soybean E00003

\author{
Zhongnan Zhang \\ Michigan State University \\ Jianjun Hao \\ Michigan State University \\ Jiazheng Yuan \\ Michigan State University \\ Qijian Song \\ USDA-ARS Soybean Genomics and Improvement Laboratory, Beltsville, MD, qijian.song@ars.usda.gov \\ D. L. Hyten \\ USDA-ARS, Soybean Genomics and Improvement Laboratory, Beltsville, Maryland, david.hyten@unl.edu
}

See next page for additional authors

Follow this and additional works at: https://digitalcommons.unl.edu/agronomyfacpub

Part of the Agricultural Science Commons, Agriculture Commons, Agronomy and Crop Sciences

Commons, Botany Commons, Horticulture Commons, Other Plant Sciences Commons, and the Plant

Biology Commons

Zhang, Zhongnan; Hao, Jianjun; Yuan, Jiazheng; Song, Qijian; Hyten, D. L.; Cregan, P. B.; Zhang, Guorong; Gu, Cuihua; Li, Ming; and Wang, Dechun, "Phytophthora Root Rot Resistance in Soybean E00003" (2014). Agronomy \& Horticulture -- Faculty Publications. 812.

https://digitalcommons.unl.edu/agronomyfacpub/812

This Article is brought to you for free and open access by the Agronomy and Horticulture Department at DigitalCommons@University of Nebraska - Lincoln. It has been accepted for inclusion in Agronomy \& Horticulture -Faculty Publications by an authorized administrator of DigitalCommons@University of Nebraska - Lincoln. 


\section{Authors}

Zhongnan Zhang, Jianjun Hao, Jiazheng Yuan, Qijian Song, D. L. Hyten, P. B. Cregan, Guorong Zhang, Cuihua Gu, Ming Li, and Dechun Wang 


\title{
Phytophthora Root Rot Resistance in Soybean E00003
}

\author{
Zhongnan Zhang, Jianjun Hao, Jiazheng Yuan, Qijian Song, David L. Hyten, \\ Perry B. Cregan, Guorong Zhang, Cuihua Gu, Ming Li, Dechun Wang^
}

\begin{abstract}
Phytophthora root rot (PRR) is a devastating disease in soybean [Glycine max (L.) Merr.] production. Michigan elite soybean E00003 is resistant to Phytophthora sojae and has been used as a resistance source in breeding. Genetic control of PRR resistance in this source is unknown. To facilitate marker-assisted selection (MAS), the PRR resistance loci in E00003 and their map locations need to be determined. In this study, a genetic mapping approach was used to identify major PRR-resistant loci in E00003. The mapping population consists of $240 \mathrm{~F}_{4}$-derived lines developed by crossing E00003 with the $P$. sojae susceptible line PI 567543C. In 2009 and 2010, the mapping population was evaluated in the greenhouse for PRR resistance against $P$. sojae races 1, 4, and 7, using modified rice (Oryza sativa L.) grain inoculation method. The population was genotyped with seven simple sequence repeat (SSR) and three single nucleotide polymorphism (SNP) markers derived from bulk segregant analysis. The heritability of resistance in the population ranged from 83 to $94 \%$. A major locus, contributing 50 to $76 \%$ of the phenotypic variation, was mapped within a $3 \mathrm{cM}$ interval in the Rps1 region. The interval was further saturated with more BARCSOY SSRs and SNPs with TaqMan assays. Two SSRs and three SNPs within the Rps1k gene were highly associated with PRR resistance in the mapping population. The major resistance gene in E00003 is either allelic or tightly linked to Rps1k.The molecular markers located in the Rps1k gene can be used to improve MAS for PRR resistance.
\end{abstract}

Z. Zhang, J. Hao, J. Yuan, C. Gu, and D. Wang, Dep. of Plant, Soil and Microbial Sciences, Michigan State Univ., East Lansing, MI 48824; Q.J. Song, D.L. Hyten, and P.B. Cregan, USDA-ARS Soybean Genomics and Improvement Laboratory, Beltsville, MD 20705; G. Zhang, Agricultural Research Center-Hays, Kansas State Univ., Hays, KS 67601; M. Li, Division of Biostatistics, Dep. of Pediatrics, Univ. of Arkansas for Medical Sciences, Little Rock, AR 72202. Received 12 Nov. 2013. ^Corresponding author (wangdech@msu.edu).

Abbreviations: BSA, bulked segregant analysis; CIM, composite interval mapping; GI, germination index; LOD, logarithm of odds; MAS, marker-assisted selection; PCR, polymerase chain reaction; PRR, Phytophthora root rot; QTL, quantitative trait loci; RIL, recombinant inbred line; SI, survival index; $\triangle$ SI, adjusted survival index; SNP, single nucleotide polymorphism; SSR, simple sequence repeat.

$\mathrm{P}$ hytophthora root rot (PRR), caused by Phytophthora sojae, is the second most destructive disease of soybean [Glycine max (L.) Merr.] in the United States (Wrather and Koenning, 2006). Significant disease epidemics have occurred in the North Central states, such as Illinois, Indiana, Michigan, Minnesota, Missouri, and Ohio, and also in the southern states, including North Carolina, Louisiana, Kentucky, and Oklahoma (Wrather and Koenning, 2006). The total estimated loss in U.S. soybean yield due to the disease was over 18 million metric tons from 1996 to 2010 (Wrather and Koenning, 2011), equivalent to 7 to 8 billion U.S. dollars (O'Brien, 2010). Yield loss can vary with weather conditions. In Ohio, for instance, yield losses averaged $11 \%$ in years with rainy springs and $8 \%$ in years with normal spring precipitation (Dorrance and Dennis, 2009).

\footnotetext{
Published in Crop Sci. 54:492-499 (2014).

doi: 10.2135/cropsci2012.11.0631

(C) Crop Science Society of America | 5585 Guilford Rd., Madison, WI 53711 USA

All rights reserved. No part of this periodical may be reproduced or transmitted in any form or by any means, electronic or mechanical, including photocopying, recording, or any information storage and retrieval system, without permission in writing from the publisher. Permission for printing and for reprinting the material contained herein has been obtained by the publisher.
} 
Phytophthora sojae infects soybeans at any growth stage primarily via the root system. High soil moisture favors disease development since $P$. sojae zoospores are only produced in saturated soil (Ho, 1969). The disease can only be partially managed using methods such as cultural practices and seed treatments with fungicides (Dorrance and Dennis, 2009; Schmitthenner, 1985). Integrated management strategies that combine host resistance with seed treatments were studied by Dorrance et al. (2009), who concluded that selecting resistant cultivars held the greatest utility.

On the basis of the results of six decades of research, both partial and race-specific resistances to $P$. sojae have been identified (Burnham et al., 2003a; Dorrance et al., 2004). Eight loci, with a total of 15 genes, have been reported as responsible for race-specific resistance (Anderson and Buzzell, 1992; Athow and Laviolette, 1982; Athow et al., 1980; Buzzell and Anderson, 1992; Demirbas et al., 2001; Diers et al., 1992; Gao and Bhattacharyya, 2008; Kilen et al., 1974; Mueller et al., 1978; Sun et al., 2011; Weng et al., 2001).

A high-yielding Michigan soybean line, E00003, was found to be resistant to $P$. sojae races 4 and 7 in the Uniform Soybean Tests in Northern States 2002 (Crochet, 2002). It has been intensively used as a source of resistance to P. sojae in the Michigan State University (MSU) soybean breeding program. There is insufficient evidence to trace the ancestor that contributed the PRR resistance to this line, thus it is unknown whether it carries new PRR resistance genes or new alleles at existing resistance loci. The objective of this study was to characterize PRR resistance in E00003 and to develop breeder-friendly markers to facilitate marker-assisted selection.

\section{MATERIALS AND METHODS}

Genetic mapping was used to identify PRR resistance loci in E00003. Phenotypic data were obtained from greenhouse trials, and genotypic data were obtained with simple sequence repeats (SSRs) and single nucleotide polymorphisms (SNPs). Resistance loci reported in the literature were first tested with SSRs in those regions.

\section{Mapping Population}

The genetic mapping population consists of $240 \mathrm{~F}_{4}$-derived lines developed with the single seed descent method (Brim, 1966) from the cross E00003 $\times$ PI 567543 C. E00003 is resistant to $P$. sojae, whereas PI 567543C is susceptible to P. sojae. The seeds of the mapping population were harvested in the fall of 2009 in the field of the Agronomy Farm at MSU located at East Lansing, MI.

\section{Evaluation for Phytophthora sojae Resistance}

Three $P$. sojae races, 1,4 , and 7, were used to evaluate the mapping population and its two parents in the MSU Plant Science Greenhouses in a total of six trials in 2009 and 2010. In each pathogen-inoculated trial, 12 seeds from each inbred line as one replicate, plus 36 seeds from each parent as three replicates, were planted in Baccto soil mix (Michigan Peat Company). The pathogen isolates were kindly provided by Dr. Anne Dorrance from the Department of Plant Pathology at Ohio State University. The greenhouse was maintained at $26^{\circ} \mathrm{C}$ day, $15^{\circ} \mathrm{C}$ night temperature, and sodium vapor lights were used to supplement light during the day (14 h).

The rice (Oryza sativa L.) grain inoculation method originally developed for evaluation of tree species for Phytophthora resistance (Holmes and Benson, 1994) was used in this study. The rice grain inoculum was prepared in 250-mL flasks. In each 250-mL flask, 25 $\mathrm{g}$ of white long-grain rice and $20 \mathrm{~mL}$ distilled water were mixed thoroughly. The flask was covered with double-layered aluminum foil and autoclaved for $40 \mathrm{~min}$ twice in $24 \mathrm{~h}$. After cooling, the rice grains in the flask were inoculated with three disks (5-mm diam.) of $P$. sojae mycelia obtained from the margin of an actively growing culture for each race. The flask was shaken daily to prevent the grains from compacting and ensure that all grains were uniformly colonized. After about 12 to $14 \mathrm{~d}$ of incubation, the rice grains were sampled and assayed for fungal colonization on V8 medium (Miller, 1955) $2 \mathrm{~d}$ before use as inoculum. As used by Holmes and Benson (1994), the rice inoculum was mixed well with sand, incorporated into a peat-vermiculite medium and sprinkled on the surface of a tray containing tree seeds. The method was modified by burying three $P$. sojae colonized rice grains together with one soybean seed in the Baccto soil mix, which provided the most appropriate disease pressure to maximize the difference of the PRR resistance levels of the resistant and susceptible parents of the mapping population in our preliminary tests.

Each soybean seed was buried in the soil with three $P$. sojae colonized rice grains at a depth of $2.5 \mathrm{~cm}$ in 12.5-cm-deep square pots (700051C, T.O. Plastics). The 12 seeds of each line were planted in two pots with six seeds in each pot. The pots were watered every other day for $14 \mathrm{~d}$, and the numbers of live seedlings were counted. For the six trials, survival index (SI) of line $j$ for trial $i$ was calculated as follows: $\mathrm{SI}_{i j}=[$ (the number of plants of line $j$ surviving in the trial i) $/ 12] \times 100$. Survival index values of the parents, E00003 and PI $567543 \mathrm{C}$, were calculated as SI $=$ [(the number of plants surviving in the trial $i) / 36] \times 100$. The SI ranges from $0 \%$ for the most susceptible lines to $100 \%$ for the most resistant lines.

A separate germination test with non-pathogen-inoculated seeds was conducted in the greenhouse in 2010. Germination index (GI) of line $j$ was calculated as follows: $\mathrm{GI}_{j}=$ (the number of plants of line $j$ germinated/12) $\times 100$. Adjusted survival index $(\Delta \mathrm{SI})$ of line $j$ for trial $i$ was defined as follows: $\Delta \mathrm{SI}_{i j}=[$ (the number of plants of line $j$ surviving in the trial $i) /\left(12 \times \mathrm{GI}_{j}\right] \times 100$.

\section{Genetic Analysis}

Genotyping of the mapping population with SSR markers was performed as described by Zhang et al. (2010). All genomic regions that had been suggested in the literature were considered as potential PRR resistance loci (Table 1). Bulked segregant analysis (BSA), as proposed by Michelmore et al. (1991), was used to obtain possible genomic regions of major PRR resistance. For each inoculation trial, 15 resistant lines with the largest SI and 15 susceptible lines with the smallest SI were selected to form one resistant bulk pool and one susceptible bulk pool. A total of 132 SSR markers covering the genomic regions with reported PRR resistance loci were first selected to test the bulks. Genomic regions potentially associated with PRR resistance were saturated further with more SSR markers and additional BARCSOY SSR markers (Song et al., 2010). Then, a 
Table 1. Rps loci and quantitative trait loci (QTL) underlying resistance to Phytophthora root rot and their locations on the soybean [Glycine max (L.) Merr.] composite map. Linkage group names, marker names, and marker positions are updated as shown on soybean composite map (Song et al., 2004). Table contents updated according to Cornelius et al. (2005).

\begin{tabular}{|c|c|c|c|}
\hline $\begin{array}{l}\text { Rps loci } \\
\text { or QTL }\end{array}$ & $\begin{array}{l}\text { Linkage } \\
\text { group }\end{array}$ & Flanking markers (cM) & Reference \\
\hline$R p s 1$ & $\mathrm{~N}$ & Satt159-Satt009 (27.1-28.5) & Weng et al., 2001 \\
\hline Rps2 & J & A233_1-A724_1 (83.2-84.9) & $\begin{array}{c}\text { Diers et al., 1992; } \\
\text { Demirbas et al., } 2001\end{array}$ \\
\hline Rps3 & $\mathrm{F}$ & A757_1-R045_1 (63.1-70.1) & $\begin{array}{c}\text { Diers et al., 1992; } \\
\text { Demirbas et al., } 2001\end{array}$ \\
\hline Rps4 & G & A586_2 (111.2) & $\begin{array}{c}\text { Diers et al., 1992; } \\
\text { Demirbas et al., } 2001\end{array}$ \\
\hline Rps5 & $\mathrm{G}^{+}$ & T005_2 (81.5) & $\begin{array}{c}\text { Diers et al., 1992; } \\
\text { Demirbas et al., } 2001\end{array}$ \\
\hline Rps6 & G & Not defined & Demirbas et al., 2001 \\
\hline Rps7 & $\mathrm{N}$ & Satt009-Satt125 (28.5-40.6) & Weng et al., 2001 \\
\hline QTL & $\mathrm{F}$ & Satt252-Satt423 (16.1-20.6) & Burnham et al., 2003a \\
\hline QTL & D1b & Satt266-Satt579 (59.6-75.9) & Burnham et al., 2003a \\
\hline RpsYu25 & $\mathrm{N}$ & Sat_186-Satt530 (30.1-32.8) & Sun et al., 2011 \\
\hline
\end{tabular}

Ilt is possible that Rps5 is on linkage group G. (Diers et al., 1992; Demirbas et al., 2001).

subpopulation of 94 individual lines, as well as the two parents, was genotyped with polymorphic and trait-associated markers identified by BSA. The remaining lines of the entire mapping population were then genotyped with the markers that showed association with PRR resistance in the initial set of 94 lines.

Ten DNA samples including the susceptible and resistant parents, two segregating bulks, and six resistant inbred lines from the mapping population were genotyped with the Illumina Infinium BeadChip (Illumina, Inc.) containing 52,041 soybean SNP markers (Song et al., 2013). Three polymorphic SNPs associated with PRR resistance among the 10 samples were selected as candidates for TaqMan SNP allele-specific genotyping assays for the population. The sequences were subjected to the Customer TaqMan Assay Design Tools of Applied Biosystems (ABI) to obtain allelespecific primers and probes, which were synthesized by ABI. The entire mapping population was genotyped with allele-specific SNP Assays. TaqMan probe-based polymerase chain reactions (PCRs) were performed in 384-well plates with a total volume of $3 \mathrm{uL} /$ well on a LightCycler 480 (Roche Applied Science). The PCR reaction mixture for the TaqMan assay consisted of $20 \mathrm{ng}$ of genomic DNA, 0.15 uL of 10X TaqMan Assay, and $1.5 \mathrm{uL}$ of $2 \mathrm{X}$ ABI Genotyping Master mix containing a modified Taq DNA polymerase, reaction buffer, $\mathrm{MgCl}_{2}$, and dNTPs (ABI). After 10 min preincubation at $95^{\circ} \mathrm{C}, 45 \mathrm{PCR}$ cycles were conducted with $10 \mathrm{sec}$ denaturation at $95^{\circ} \mathrm{C}, 30 \mathrm{sec}$ annealing at $60^{\circ} \mathrm{C}$, and $10 \mathrm{sec}$ extension at $72^{\circ} \mathrm{C}$. A final melting cycle for nonspecific amplicon screening was performed by raising the temperature to $95^{\circ} \mathrm{C}$ for 10 $\mathrm{sec}$, lowering the temperature to $40^{\circ} \mathrm{C}$ for $30 \mathrm{sec}$, then increasing the temperature to $83^{\circ} \mathrm{C}$ with continuous fluorescent acquisition followed by cooling to $40^{\circ} \mathrm{C}$ on the LightCycler 480 . Data were analyzed by the Roche Applied Science software version 1.5.0.

\section{Data Analysis}

Survival index from the six inoculated trials were calculated and analyzed by the statistical software R. The broad-sense heritability $\left(H^{2}\right)$ (Fehr, 1987) of PRR resistance to different races was calculated in a fixed model as follows:

$$
H^{2}=\frac{\sigma_{g}^{2}}{\sigma_{g}^{2}+\sigma_{e}^{2} / r},
$$

where $\sigma_{\mathrm{g}}{ }^{2}$ is the mean square for genotypes, $\sigma_{\mathrm{e}}{ }^{2}$ is the error mean square, and $r$ is the number of years. The 2 yr were treated as two replications, with $r=2$. Correlation coefficients for SI with the same pathogen race in 2009 and 2010 were estimated. Two-sample $t$ test was conducted to compare the means of the $2 \mathrm{yr}$ for each race. Tukey's procedure was used for multiple line comparisons. A linkage map was constructed using JoinMap 3.0 with the Kosambi function and a logarithm of odds (LOD) score of 3 (Van Ooijen and Voorrips, 2001). Composite interval mapping (CIM) was performed using QTL Cartographer V2.5 (Wang et al., 2008) to locate PRR resistance loci with LOD threshold determined by 1000 permutations (significant level $\alpha=0.05)$. The plots of LOD scores and the locus positions were generated using MapChart (Voorrips, 2002). Germination index and $\Delta$ SI for the six trials were calculated and analyzed as separate phenotypic traits in quantitative trait loci (QTL) analysis using CIM method in QTL Cartographer V2.5. Chi-square test was used to determine if the observed ratio of the genotypic classes fitted the expected ratio.

\section{RESULTS AND DISCUSSION Phenotype Distribution}

Phytophthora sojae races 1, 4, and 7 were used to screen the mapping population for resistance to PRR. Survival index of the susceptible parent PI 567543C varied from 0.0 to $5.6 \%$, while that of the resistant parent E00003 ranged from 41.7 to $91.7 \%$ (Table 2). E00003 showed significantly lower SI means in trials inoculated with race 4 (44.4\%) than with race $1(91.7 \%)$ in 2009 at significant level $\alpha=$ 0.05, which indicates that E00003 is less resistant to race 4 than to race 1 . The SIs of the three replicates were very closely correlated (pairwise correlation coefficients $=0.79$, 0.88 , and 0.93 ; all $p$ values $<0.01)$. Therefore, one replication was sufficient for each trial. Two-sample $t$ test showed there was no significant difference between the $2 \mathrm{yr}$ for races 1 and 7 , indicating that year is not a confounding factor in the heritability calculation ( $p$ value $=0.47$ and 0.25 , respectively, for races 1 and 7$)$. A significant difference ( $p$ value $=0.00065)$ was detected in race 4 between the 2 $\mathrm{yr}$; therefore, the heritability was not estimated for race 4. In races 1 and 7 , the broad sense heritability ranged from 83 to $94 \%$. The correlation coefficients of race-specific SI between the 2 yr were all significant for the three $P$. sojae races, $0.89,0.77$, and 0.78 , respectively. Continuous phenotypic distribution of SI with major peaks was observed for each trial, with SI ranging from 0 to $100 \%$ (Fig. 1). Among the entire mapping population, $90 \%$ of the lines had a GI above $87.5 \%$. Germination index was applied as a phenotypic trait in QTL analysis, however no QTL with LOD 
Table 2. Survival index (mean $\pm S E$ ) of the mapping population with $240 \mathrm{~F}_{4}$-derived lines and the parents E00003 and PI $567543 \mathrm{C}$ in the six Phytophthora sojae inoculated greenhouse trials conducted in 2009 and 2010. Survival index = the number of surviving plants/total number of seeds planted $\times 100 \%$.

\begin{tabular}{|c|c|c|c|c|c|c|}
\hline \multirow[b]{3}{*}{ Trial } & \multirow[b]{3}{*}{ Year } & \multirow[b]{3}{*}{$\begin{array}{c}P . \text { sojae } \\
\text { race }\end{array}$} & \multicolumn{4}{|c|}{ Survival index } \\
\hline & & & \multicolumn{2}{|c|}{ Parents } & \multirow{2}{*}{$\begin{array}{c}\mathrm{F}_{4} \text {-derived } \\
\frac{\text { lines }}{\text { Population }} \\
\text { mean } \pm \mathrm{SE}\end{array}$} & \multirow[b]{2}{*}{ Range } \\
\hline & & & $\begin{array}{c}\mathrm{PI} \\
567543 \mathrm{C}\end{array}$ & E00003 & & \\
\hline 1 & 2009 & 1 & $0.0 \pm 0.0$ & $91.7 \pm 0.0$ & $48.7 \pm 36.2$ & $0.0-100.0$ \\
\hline 2 & & 4 & $0.0 \pm 0.0$ & $44.4 \pm 25.5$ & $26.8 \pm 27.0$ & $0.0-100.0$ \\
\hline 3 & & 7 & $5.6 \pm 4.8$ & $69.4 \pm 29.3$ & $46.7 \pm 34.2$ & $0.0-100.0$ \\
\hline 4 & 2010 & 1 & $0.0 \pm 0.0$ & $61.1 \pm 17.3$ & $51.2 \pm 39.7$ & $0.0-100.0$ \\
\hline 5 & & 4 & $0.0 \pm 0.0$ & $41.7 \pm 25.0$ & $36.8 \pm 32.7$ & $0.0-100.0$ \\
\hline 6 & & 7 & $2.8 \pm 4.8$ & $80.6 \pm 12.7$ & $50.7 \pm 39.1$ & $0.0-100.0$ \\
\hline
\end{tabular}

more than 1.0 were detected within the region of interest (data not shown). Further, we calculated the $\Delta$ SI and conducted QTL analysis with $\Delta$ SI. There was only a slight improvement in heritability and $R^{2}$ in the QTL analysis over the unadjusted SI (data not shown). For simplicity, only the unadjusted SI and the analysis are presented.

\section{Phytophthora Root Rot Resistance Locus Mapping}

The resistant and susceptible bulks were first genotyped with markers in close proximity to previously identified $R p s$ resistance loci (Table 1) to investigate whether the Rps loci in E00003 were among those reported in the literature. From the BSA, a cluster of SSR markers on Chromosome 3 (linkage group $\mathrm{N}$ ) were polymorphic between the PRR resistant and susceptible bulks. The polymorphic SSR markers were further tested with 94 lines from the mapping population. Simple sequence repeat markers Satt631, Satt675, Satt485, Satt584, and Satt624 were associated with the phenotypic data and were confirmed by genotyping the remainder of the population. The five SSR markers formed one linkage group in the linkage analysis with JoinMap (Van Ooijen and Voorrips, 2001), and a major QTL was located in a 20-cM interval between Satt631 and Satt675 when the data were analyzed using the CIM method in WinQTLCart 2.5 (Wang et al., 2008) (data not shown). The interval was in the $R p s 1$ region (Gardner et al., 2001). Though Rps1 is close to $R p s 7, R p s 7$ was eliminated because it is susceptible to races 1, 4, 7, and 25 (Dorrance et al., 2004). Within the region flanked by Satt631 and Satt675, there is another recently identified Rps locus, RpsYu25 (Sun et al., 2011). The authors claimed that $R p s Y u 25$ is a novel locus, on the basis of different responses to a set of pathogen isolates, and developed a flow chart as a dichotomous key to differentiate Rps loci. The set of pathogens used in that study was not comparable with pathogen isolates we used; thus, it was not possible to eliminate $R p s \mathrm{Yu} 25$ as a candidate.
With the goal of developing breeder-friendly SSR s for marker-assisted selection (MAS), a total of 220 BARCSOY SSRs (Song et al., 2010) between Satt631 and Satt675 were screened with the bulks, and polymorphic BARCSOY SSRs were further used to genotype the entire population. Two BARCSOY markers, BARCSOYSSR_03_0249 and BARCSOYSSR_03_0250, were strongly associated with the Phytophthora resistance loci in E00003. These two SSR markers happen to reside within the $P$. sojae resistant gene Rps1k identified by Gao et al. (2005). To further identify the region containing the resistance locus in E00003, a new linkage map was constructed by adding the two BARCSOY SSR s to the five SSR s mapped earlier (data not shown). The marker order followed the same order as the consensus map and the latest map integrated with BARCSOY SSRs (Song et al., 2004; Song et al., 2010). The interval containing the resistant locus was less than $2 \mathrm{cM}$ between marker BARCSOYSSR_03_0250 and Satt675. The LOD score was estimated at 28.9 to 53.3 . The $R^{2}$ ranged from 0.46 to 0.67 , with additive effect from 18.8 to $33.4 \%$. Since the $R^{2}$ only partially explained the total genetic variance as estimated by heritability, we investigated whether other PRR resistance loci existed. A total of 1328 SSRs evenly spread through the entire genome were screened with the DNA bulks, and only 15 SSRs were found to distinguish the bulks. However, none showed association with PRR resistance in the entire mapping population. Therefore, no other major PRR resistance loci were detected in E00003.

\section{Analysis with Single Nucleotide Polymorphism Markers}

Of the 52,041 SNPs on the soybean SoySNP50K BeadChip, $17,830(34.3 \%)$ were polymorphic between the two parents. Among these SNPs, 200 (1.1\%) had alternative alleles present in the E00003 resistant parent and resistant bulk versus the susceptible parent PI 567543C and the susceptible bulk. Among the genotypes of the six resistant inbred lines from the mapping population for these 200 SNPs, 76 SNPs were associated with the PRR resistance. All of these 76 SNPs are located on Chromosome 3 (linkage group N), confirming that no other major PRR resistance loci are present. Of the 76 SNPs from physical positions of 2,025,790 bp to $22,595,547 \mathrm{bp}$ on Chromosome 3, 56 SNPs (73.7\%) are clustered within the region $3,613,821$ bp to $5,948,099 \mathrm{bp}$, covering the Rps $1 \mathrm{k}$ gene region, $(4,457,810$ bp to $4,641,921$ bp) (Gao and Bhattacharyya, 2008). This gene family encoding coiled coil-nucleotide binding-leucine rich repeat (CCNB-LRR)-type proteins could be involved in a hypersensitive response, producing pathogen recognition and defense response initiation (Gao and Bhattacharyya, 2008). Three SNP markers were designed for TaqMan SNP allele-specific genotyping assays at the following positions, MSUSNP03-1 (BARC_1.01_Gm03_4487138_A_C; the numeric string indicates SNP physical position), MSUSNP03-2 

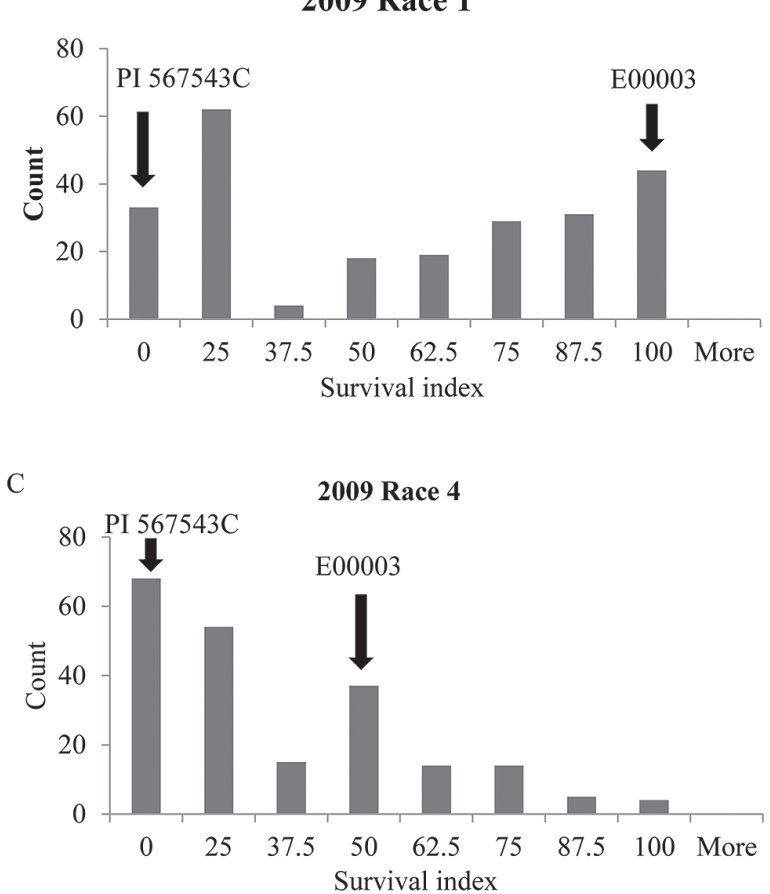

$\mathrm{E}$

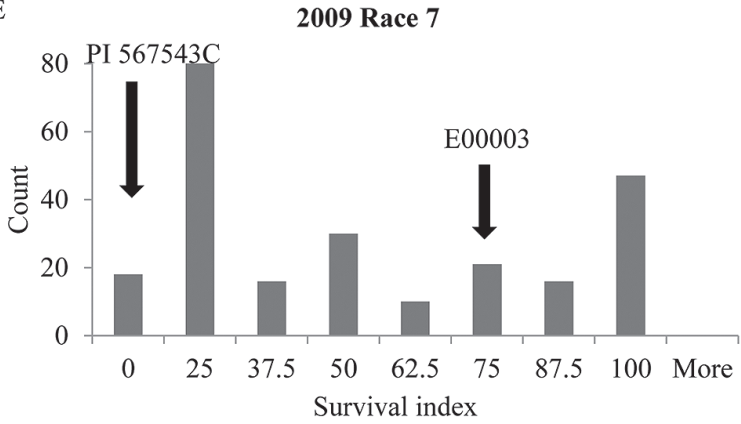

$\mathrm{B}$
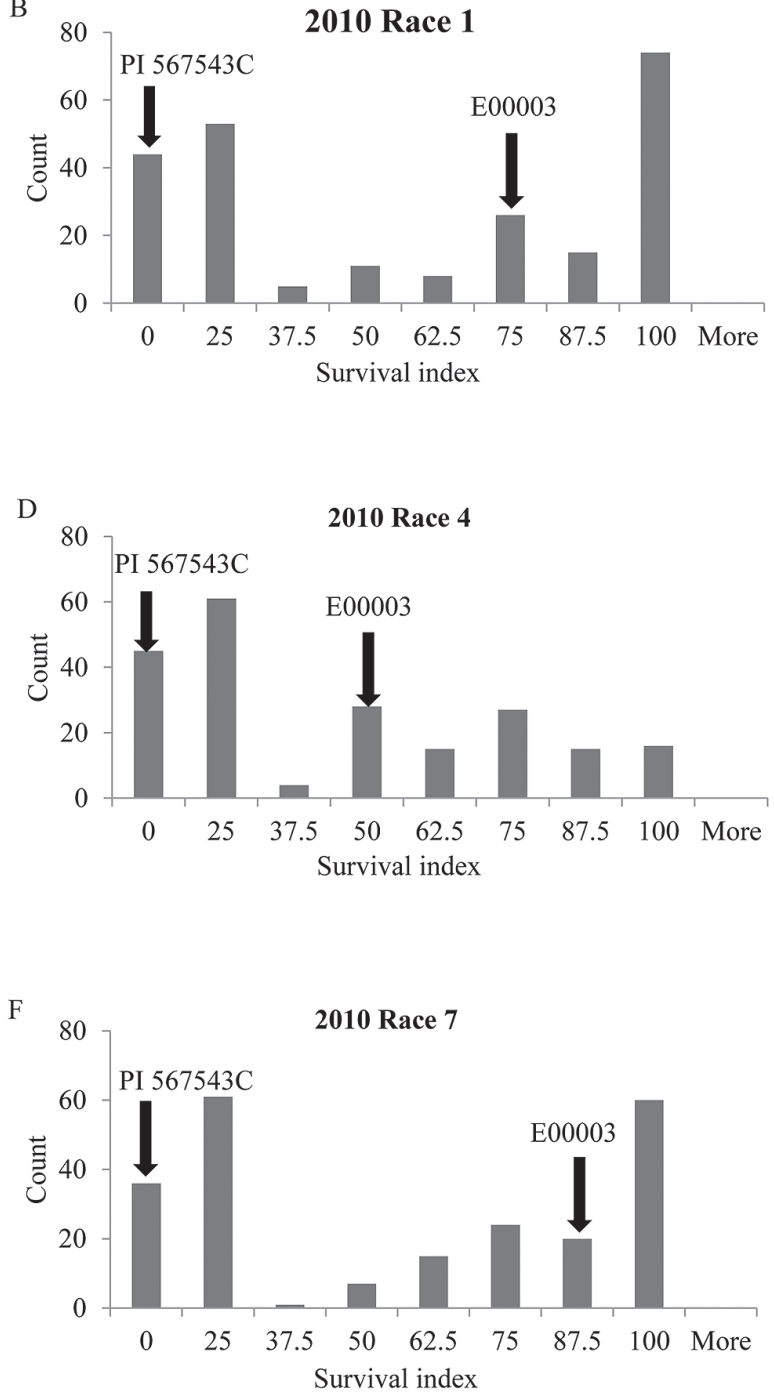

Figure 1. Phenotypic distribution of survival index (SI) of the mapping population among $240 \mathrm{~F}_{4}$-derived lines from PI $567543 \mathrm{C} \times \mathrm{E} 00003$. Parental Sls are indicated by arrows. Survival index was calculated as: Slij = (the number of plants surviving of line $j$ in the inoculated trial i/12) $\times 100$.

Table 3. Segregation ratio of different genotypes of the three single nucleotide polymorphism (SNP) markers in the $\mathrm{F}_{4}-$ derived mapping population E00003 x PI 567543C. The three SNP markers are MSUSNP03-1 (BARC_1.01_Gm03_4487138_A_C), MSUSNP03-2 (BARC_1.01_Gm03_4563499_G_A), and MSUSNP03-3 (BARC_1.01_Gm03_4610670_C_T).

\begin{tabular}{|c|c|c|c|c|c|c|}
\hline $\begin{array}{l}\text { Molecular } \\
\text { markers }\end{array}$ & $\begin{array}{c}\text { Homozygous of } \\
\text { resistance allele } \\
\text { of E00003 }\end{array}$ & Heterozygous & $\begin{array}{l}\text { Homozygous of } \\
\text { susceptible allele } \\
\text { of PI } 567543 \mathrm{C}\end{array}$ & $\begin{array}{c}\text { Expected ratio in } \\
\mathrm{F}_{4} \text { generation }\end{array}$ & $\begin{array}{l}\text { Chi-square } \\
\text { statistics }\end{array}$ & $P$ value \\
\hline & \multicolumn{6}{|c|}{ Number of the individuals in the population ${ }^{\dagger}$} \\
\hline MSUSNP03-1 & 108 & 26 & 100 & $7: 2: 7$ & 0.73 & 0.39 \\
\hline MSUSNP03-2 & 107 & 26 & 103 & $7: 2: 7$ & 0.55 & 0.46 \\
\hline MSUSNP03-3 & 105 & 24 & 101 & $7: 2: 7$ & 0.98 & 0.32 \\
\hline
\end{tabular}

${ }^{\dagger} \mathrm{A}$ total of $240 \mathrm{~F}_{4}$-derived lines of the mapping population $\mathrm{E} 00003 \times \mathrm{PI} 567543 \mathrm{C}$ were genotyped; individual with missing value in genotyping was not shown in this table. ¥Allele-specific SNP markers designed from the SoySNP50K BeadChip (Song et al., 2013).

(BARC_1.01_Gm03_4563499_G_A), and MSUSNP03-3 (BARC_1.01_Gm03_4610670_C_T) (Supplemental Table). The entire mapping population was genotyped with those SNP markers using TaqMan SNP allele-specific genotyping assays. Genetic analysis with Chi-square test on the segregation ratio of different genotypic classes revealed no significant difference between the observed and the expected ratio in the $\mathrm{F}_{4}$ generation (Table 3), indicating there is no segregation distortion in the mapping population.

A new linkage map was constructed by adding the three SNPs (Fig. 2), and QTL analysis was performed using this new map. The QTL positions on the new map 
Strong evidence of additive gene action was detected, since the average SI for the heterozygous type was significantly smaller than that for the homozygous resistant type, sig-

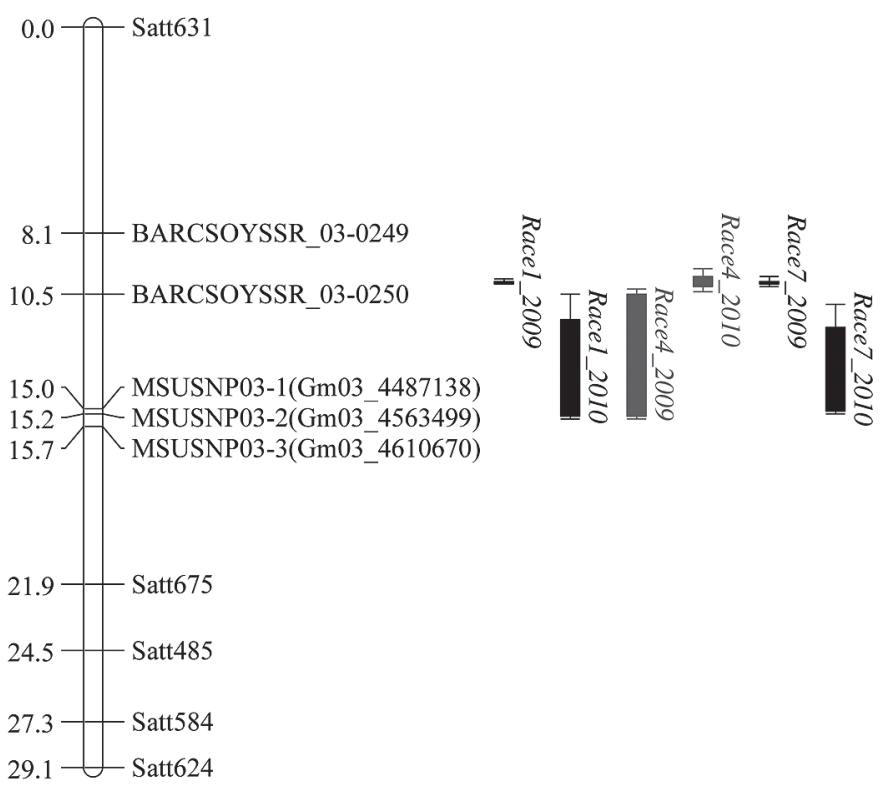

Figure 2. Location of the Phytophthora root rot resistance locus in E00003 as mapped with the composite interval mapping method. The linkage map of the simple sequence repeat markers and the single nucleotide polymorphism markers was constructed with the genotypic data from the mapping population. Bars show intervals of loci mapped in the different trials.

are shown in Fig. 2, and LOD scores and $R^{2}$ are given in Table 4. The LOD scores were estimated to be between 32.3 and 62.6. The $R^{2}$ ranged from 0.50 to 0.76 , with additive effects from 19.2 to $33.0 \%$. These results indicated that about 50 to $76 \%$ of the phenotypic variation can be explained by the resistance locus in E00003. The remaining phenotypic variation was due to some other minor effect QTL or experimental errors. Though Phytophthora resistance investigated here is encoded by a major gene, the resistance gene was successfully identified by the QTL mapping method in this study. Quantitative trait loci mapping methods have also proven successful in identifying major genes in other studies (Zhang et al., 2010, 2013).

The positions of LOD peaks in Table 4 were estimated at 24.4 to $26.3 \mathrm{cM}$ on the basis of the position of markers Satt631 and Satt675 from soybean consensus map (Song et al., 2004). Considering physical positions, the QTL region is located within interval 4,475,877 to 4,563,799 bp (Fig. 2), within the Rps1k interval, 4,457,810 to 4,641,921 bp (Gao and Bhattacharyya, 2008). RpsYu25 is located between $3,338,620$ and 3,465,436 bp by converting the flanking markers Satt152 and Sat_186 from interval 30.1 to $32.8 \mathrm{cM}$ (Song et al., 2010; Sun et al., 2011).

To validate the gene action of the resistance allele at Rpslin E00003, SI for each genotype of the three polymorphic allele-specific SNP markers was estimated using the combined SI of $2 \mathrm{yr}$ of data for the same race (Table 5). nificantly larger than that for the homozygous susceptible type, and not significantly different from the average of the two homozygous types at the significant level of $\alpha=0.05$.

In spite of advances in quantitative molecular genetics, owing to genomics, computation, and statistics, the bottleneck in genetic analysis is now phenotyping rather than genotyping (Walsh, 2009). The detection of Rps1 locus in the Michigan elite line E00003 has shown that the rice grain inoculation method is an effective high-throughput phenotyping approach to detect $R p$ s loci with major effects. The method provides the opportunity for the soil-borne pathogen to interact with its host, mimicking natural infection of soybean, and to avoid injury to epidermal tissues, which occurs in the hypocotyl splitting method. The rice grain method saves labor and time of splitting soybean seedlings. Within $14 \mathrm{~d}$, thousands of rice grains can be prepared in a single batch as pathogen inoculum, and they are easier to handle. Compared with the vermiculite layer test (Thomison et al., 1991), growing the pathogen on one layer of agar in a petri dish for each single pot is unnecessary. However, to detect partial resistance to PRR, lesion length measurement using a slant board test (Burnham et al., 2003a) has proven effective (Tucker et al., 2010). Although there might be some confounding effect with germination rate or soil factors, the validity of our findings was not affected.

Phytophthora resistance in E00003 maps to the Rps1 locus. To determine whether it is $R p s 1 \mathrm{k}$, additional crosses need to be made between E00003 and the original Rps $1 \mathrm{k}$ parent-Williams 82 or Kingwa (Dorrance et al., 2004, Kasuga et al., 1997). The resistance gene in E00003 could be a new allele at the Rps1 locus or a new gene tightly linked to Rps1. Most importantly, two SSRs and three SNP allele-specific endpoint genotyping markers, MSUSNP03-1 (BARC_1.01_Gm03_4487138_A_C), MSUSNP03-2 (BARC_1.01_Gm03_4563499_G_A), and MSUSNP03-3 (BARC_1.01_Gm03_4610670_C_T), were identified and developed for the resistant locus in line E00003. The SNP markers are also polymorphic among commercial varieties entered in Michigan Soybean Performance Trials and significantly associated with the Rps1 reported by companies that entered the varieties to the trials (data not shown). With these breeder-friendly SSR and SNP markers, marker-assisted selection can be performed efficiently and effectively by using E00003 or other soybean lines containing the E00003 resistance locus as the source for PRR resistance.

\section{Acknowledgments}

This project was made possible by the Dr. Mericle Scholarships. The authors would like to thank Dr. Anne Dorrance for the pathogen isolates of Phytophthora sojae and Xiaohong Lu for valuable technical support and assistance in the laboratory. The authors also thank Dr. Frank Dennis for his editorial assistance. 
Table 4. Phytophthora root rot resistance locus detected in the mapping population E00003 $\times$ PI $567543 \mathrm{C}$ using the composite interval mapping (CIM) method. Chromosome 3 (Linkage Group N) is based on SoyBase (Grant et al., 2010).

\begin{tabular}{|c|c|c|c|c|c|c|c|}
\hline Trial & Year & $\begin{array}{c}\text { Phytophthora } \\
\text { sojae race }\end{array}$ & $\begin{array}{c}\text { Peak } \\
\text { position }^{\dagger}\end{array}$ & Marker near the peak & $\begin{array}{c}\text { LOD } \\
\text { (threshold) }^{\ddagger}\end{array}$ & $R^{2}$ & $\begin{array}{c}\text { Additive } \\
\text { effect }\end{array}$ \\
\hline & & & $\mathrm{cM}$ & & & & \\
\hline 1 & 2009 & 1 & 24.4 & BARCSOYSSR_03_0250 & $62.6(3.7)$ & 0.76 & 31.6 \\
\hline 2 & & 4 & 26.3 & MSUSNP03-1 (BARC_1.01_Gm03_4487138_A_C)§ & $32.3(2.5)$ & 0.50 & 19.2 \\
\hline 3 & & 7 & 24.4 & BARCSOYSSR_03_0250 & $32.1(2.4)$ & 0.59 & 26.8 \\
\hline 4 & 2010 & 1 & 25.4 & BARCSOYSSR_03_0250 & $56.01(2.8)$ & 0.69 & 33.0 \\
\hline 5 & & 4 & 24.4 & BARCSOYSSR_03_0250 & $36.6(3.2)$ & 0.56 & 24.8 \\
\hline 6 & & 7 & 26.2 & MSUSNP03-1 (BARC_1.01_Gm03_4487138_A_C) & $58.9(3.6)$ & 0.70 & 32.9 \\
\hline
\end{tabular}

†Peak position converted according to consensus map (Song et al., 2004).

‡Logarithm of odds (LOD) score threshold for each trial determined by 1000 permutations in CIM by WinQTLCart (Wang et al., 2008).

§ingle nucleotide polymorphism markers from Song et al. (2013).

Table 5. Average survival index for different genotypes of the three single nucleotide polymorphism (SNP) markers in the mapping population E00003 x PI 567543C. Numbers followed by different letters within the same row are significantly different at $(P<0.05)$. The three SNP markers are MSUSNP03-1 (BARC_1.01_Gm03_4487138_A_C), MSUSNP03-2 (BARC_1.01_Gm03_4563499_G_A), and MSUSNP03-3 (BARC_1.01_Gm03_4610670_C_T).

\begin{tabular}{|c|c|c|c|c|}
\hline SNP Marker & $\begin{array}{c}\text { E00003 } \\
\text { type }\end{array}$ & $\begin{array}{l}\text { Heterozy- } \\
\text { gous type }\end{array}$ & $\begin{array}{c}\text { PI 567543C } \\
\text { type }\end{array}$ & $\begin{array}{l}\text { Average of } \mathrm{PI} \\
567543 \mathrm{C} \text { and } \\
\text { E00003 types }\end{array}$ \\
\hline & \multicolumn{4}{|c|}{ Race 1} \\
\hline MSUSNP03-1 ${ }^{\dagger}$ & $82.8 \mathrm{a}$ & $58.7 b$ & $13.6 c$ & $48.2 b$ \\
\hline MSUSNP03-2 & $82.6 a$ & $57.5 b$ & $14.2 \mathrm{c}$ & $48.4 b$ \\
\hline \multirow[t]{2}{*}{ MSUSNP03-3 } & $82.1 \mathrm{a}$ & $57.1 \mathrm{~b}$ & $12.7 \mathrm{c}$ & $47.4 b$ \\
\hline & \multicolumn{4}{|c|}{ Race 4} \\
\hline MSUSNP03-1 & $53.9 a$ & $31.1 b$ & $5.9 \mathrm{c}$ & $29.9 b$ \\
\hline MSUSNP03-2 & $53.4 a$ & $29.2 b$ & $6.5 c$ & $30.0 \mathrm{~b}$ \\
\hline \multirow[t]{2}{*}{ MSUSNP03-3 } & $54.0 a$ & $29.4 b$ & $7.2 \mathrm{c}$ & $30.6 b$ \\
\hline & \multicolumn{4}{|c|}{ Race 7} \\
\hline MSUSNP03-1 & $79.6 a$ & $59.8 b$ & $14.6 \mathrm{c}$ & $47.1 b$ \\
\hline MSUSNP03-2 & $79.1 a$ & $58.5 b$ & $15.7 \mathrm{c}$ & $47.4 b$ \\
\hline MSUSNP03-3 & $79.1 \mathrm{a}$ & $59.6 b$ & $15.5 c$ & $47.3 b$ \\
\hline
\end{tabular}

†Allele-specific SNP markers designed from the SoySNP50K BeadChip (Song et al., 2013).

\section{References}

Anderson, T.R., and R.I. Buzzell. 1992. Inheritance and linkage of the Rps7 gene for resistance to Phytophthora rot of soybean. Plant Dis. 76:958-959. doi:10.1094/PD-76-0958

Athow, K.L., and F.A. Laviolette. 1982. Rps6, a major gene for resistance to Phytophthora-megasperma f. sp glycinea in soybean. Phytopathology 72:1564-1567. doi:10.1094/Phyto-72-1564

Athow, K.L., F.A. Laviolette, E.H. Mueller, and J.R. Wilcox. 1980. A new major gene for resistance to Phytophthora-megasperma var. sojae in soybean. Phytopathology 70:977-980. doi:10.1094/ Phyto-70-977

Brim, C.A. 1966. A modified pedigree method of selection in soybeans. Crop Sci. 6:220. doi:10.2135/cropsci1966.0011183X000 $600020041 x$

Burnham, K.D., A.E. Dorrance, T.T. VanToai, and S.K.S. Martin. 2003a. Quantitative trait loci for partial resistance to $P h y$ tophthora sojae in soybean. Crop Sci. 43:1610-1617. doi:10.2135/ cropsci2003.1610

Buzzell, R.I., and T.R. Anderson. 1992. Inheritance and race reaction of a new soybean Rps1 allele. Plant Dis. 76:600-601. doi:10.1094/PD-76-0600

Cornelius, B., P. Chen, Y. Chen, N. de Leon, J.G. Shannon, and D. Wang. 2005. Identification of QTLs underlying water-logging tolerance in soybean. Mol. Breed. 16:103-112. doi:10.1007/ s11032-005-5911-2

Crochet, W.D. 2002. The uniform soybean tests, northern states. Purdue University, West Lafayette, IN.

Demirbas, A., B.G. Rector, D.G. Lohnes, R.J. Fioritto, G.L. Graef, P.B. Cregan, R.C. Shoemaker, and J.E. Specht. 2001. Simple sequence repeat markers linked to the soybean Rps genes for Phytophthora resistance. Crop Sci. 41:1220-1227. doi:10.2135/ cropsci2001.4141220x

Diers, B.W., L. Mansur, J. Imsande, and R.C. Shoemaker. 1992. Mapping Phytophthora resistance loci in soybean with restriction-fragment-length-polymorphism markers. Crop Sci. 32:377383. doi:10.2135/cropsci1992.0011183X003200020020x

Dorrance, A., and M. Dennis. 2009. Phytophthora damping off and root rot of soybean, fact sheet. Agriculture and Natural Resources. Ohio State University, Columbus, $\mathrm{OH}$.

Dorrance, A.E., H. Jia, and T.S. Abney. 2004. Evaluation of soybean differentials for their interaction with Phytophthora sojae. Plant Health Prog. doi: 10.1094/PHP-2004-0309-01-RS.

Dorrance, A.E., A.E. Robertson, S. Cianzo, L.J. Giesler, C.R. Gran, M.A. Draper, A.U. Tenuta, and T.R. Anderson. 2009. Integrated management strategies for Phytophthora sojae combining host resistance and seed treatments. Plant Dis. 93:875882. doi:10.1094/PDIS-93-9-0875

Fehr, W.R. 1987. Principles of cultivar development: Theory and technique. MacMillan, New York.

Gao, H., and M.K. Bhattacharyya. 2008. The soybean-Phytophthora resistance locus $R p s 1-\mathrm{k}$ encompasses coiled coil-nucleotide binding-leucine rich repeat-like genes and repetitive sequences. BMC Plant Biol. 8:29. doi:10.1186/1471-2229-8-29

Gao, H.Y., N.N. Narayanan, L. Ellison, and M.K. Hattacharyya. 2005. Two classes of highly similar coiled coil-nucleotide binding-leucine rich repeat genes isolated from the Rps1-k locus encode Phytophthora resistance in soybean. Mol PlantMicrobe Interact. 18:1035-1045.

Gardner, M.E., T. Hymowitz, S.J. Xu, and G.L. Hartman. 2001. Physical map location of the Rps1-k allele in soybean. Crop Sci. 41:1435-1438. doi:10.2135/cropsci2001.4151435x

Grant, D., R.T. Nelson, S.B. Cannon, and R.C. Shoemaker. 2010. SoyBase, the USDA-ARS soybean genetics and genomics database. Nucleic Acids Res. 38:D843-D846. doi:10.1093/nar/gkp798 
Ho, H.H. 1969. Notes on the behavior of Phytophthora megasperma var. sojae in soil. Mycologia 61:835-838. doi:10.2307/3757476

Holmes, K.A., and D.M. Benson. 1994. Evaluation of Phytophthora-parasitica var. nicotianae for biocontrol of Phytophthora-parasitica on Catharanthus-roseus. Plant Dis. 78:193-199. doi:10.1094/ PD-78-0193

Kasuga, T., S.S. Salimath, J. Shi, M. Gijzen, R.I. Buzzell, and M.K. Bhattacharyya. 1997. High resolution genetic and physical mapping of molecular markers linked to the Phytophthora resistance gene Rps1-k in soybean. Mol. Plant Microbe Interact. 10:1035-1044. doi:10.1094/MPMI.1997.10.9.1035

Kilen, T.C., E.E. Hartwig, and B.L. Keeling. 1974. Inheritance of a second major gene for resistance to phytophthora rot in soybeans. Crop Sci. 14:260-262. doi:10.2135/cropsci1974.0011 183X001400020027x

Michelmore, R.W., I. Paran, and R.V. Kesseli. 1991. Identification of markers linked to disease-resistance genes by bulked segregant analysis - a rapid method to detect markers in specific genomic regions by using segregating populations. Proc. Natl. Acad. Sci. USA 88:9828-9832. doi:10.1073/pnas.88.21.9828

Miller, P.M. 1955. V-8 juice agar as a general-purpose medium for fungi and bacteria. Phytopathology 45:461-462.

Mueller, E.H., K.L. Athow, and F.A. Laviolette. 1978. Inheritance of resistance to four physiologic races of Phytophthora megasperma var sojae. Phytopathology 68:1318-1322. doi:10.1094/Phyto-68-1318

O'Brien, D. 2010. U.S. crop acreage trends and soybean/corn price ratios. http://aes.missouri.edu/delta/research/soyloss.stm (accessed 4 Oct. 2012).

Schmitthenner, A.F. 1985. Problems and progress in control of Phytophthora root rot of soybean. Plant Dis. 69:362-368. doi:10.1094/PD-69-362

Song, Q., D.L. Hyten, G. Jia, C.V. Quigley, E. Fickus, R. Nelson, and P.B. Cregan. 2013. Development and evaluation of SoySNP50K, a high-density genotyping array for soybean. PLoS ONE 8(1):E54985. doi:10.1371/journal.pone.0054985

Song, Q., L.F. Marek, R.C. Shoemaker, K.G. Lark, V.C. Concibido, X. Delannay, J.E. Specht, and P.B. Cregan. 2004. A new integrated genetic linkage map of the soybean. Theor. Appl. Genet. 109:122-128. doi:10.1007/s00122-004-1602-3

Song, Q., G.F. Jia, Y.L. Zhu, D. Grant, R.T. Nelson, E.Y. Hwang, D.L. Hyten, and P.B. Cregan. 2010. Abundance of SSR motifs and development of candidate polymorphic SSR markers (BARCSOYSSR_1.0) in soybean. Crop Sci. 50:1950-1960. doi:10.2135/cropsci2009.10.0607
Sun, S., X.L. Wu, J.M. Zhao, Y.C. Wang, Q.H. Tang, D.Y. Yu, J.Y. Gai, and H. Xing. 2011. Characterization and mapping of RpsYu25, a novel resistance gene to Phytophthora sojae. Plant Breed. 130:139-143. doi:10.1111/j.1439-0523.2010.01794.x

Thomison, P.R., C.A. Thomas, and W.J. Kenworthy. 1991. Tolerant and root-resistant soybean cultivars-reactions to Phytophthora rot in inoculum-layer tests. Crop Sci. 31:73-75. doi:10.2135/cropsci1991.0011183X002600010018x

Tucker, D.M., M.A.S. Maroof, S. Mideros, J.A. Skoneczka, D.A. Nabati, G.R. Buss, I. Hoeschele, B.M. Tyler, S.K. St. Martin, and A.E. Dorrance. 2010. Mapping quantitative trait loci for partial resistance to Phytophthora sojae in a soybean interspecific cross. Crop Sci. 50:628-635. doi:10.2135/cropsci2009.03.0161

Van Ooijen, J.W., and R.E. Voorrips. 2001. JoinMap 3.0. Software for the calculation of genetic linkage maps in experimental populations. Kyazma BV, Wageningen, Netherlands.

Voorrips, R.E. 2002. MapChart: Software for the graphical presentation of linkage maps and QTLs. J. Hered. 93:77-78. doi:10.1093/jhered/93.1.77

Walsh, B. 2009. Quantitative genetics, version 3.0: Where have we gone since 1987 and where are we headed? Genetica (The Hague) 136:213-223.

Wang, S., C.J. Basten, and Z.B. Zeng. 2008. Windows QTL cartographer 2.5. Dep. of Statistics, North Carolina State University, Raleigh. http://statgen.ncsu.edu/qtlcart/WQTLCart.htm (accessed 4 Oct. 2012).

Weng, C., K. Yu, T.R. Anderson, and V. Poysa. 2001. Mapping genes conferring resistance to Phytophthora root rot of soybean, Rps1a and Rps7. J. Hered. 92:442-446. doi:10.1093/ jhered/92.5.442

Wrather, J.A., and S.R. Koenning. 2006. Estimates of disease effects on soybean yields in the United States, 2003 to 2005. J. Nematol. 38:173-180.

Wrather, J.A., and S.R. Koenning. 2011. Soybean disease loss estimates for the United States, 1996-2010. Delta Research Center Agricultural Experiment Station, Univ. of Missouri. http://aes. missouri.edu/delta/research/soyloss.stm (accessed 4 Oct. 2012).

Zhang, G., C. Gu, and D. Wang. 2010. A novel locus for soybean aphid resistance. Theor. Appl. Genet. 120:1183-1191. doi:10.1007/s00122-009-1245-5

Zhang, G., C. Gu, and D. Wang. 2013. Mapping and validation of a gene for soybean aphid resistance in PI 567537. Mol. Breed. 10.1007/s11032-013-9857-5. 